\title{
EFFECT OF BARK STRIPPING ON THE ELECTRICAL IMPEDANCE OF QUERCUS SUBER LEAVES
}

\author{
Abdelillah Hakam ${ }^{1 \star}$, Mariange Magne Takam ${ }^{1}$, Mustapha Chokairi ${ }^{2}$, Noureddine Alami Chantoufi, \\ Zeinedine Hamoutahra ${ }^{1}$, Abdelaziz El Alami ${ }^{3}$, Abderrahim Famiri ${ }^{3}$, Mohsine Ziani ${ }^{1}$, Joseph Gril ${ }^{4}$
}

\begin{abstract}
This study examined the effect of bark stripping on the electrical impedance parameters of cork oak young leaves between $40 \mathrm{~Hz}$ and $100 \mathrm{kHz}$. This was a new application of the electrical impedances spectroscopy (EIS) in plant science. Various stripping coefficients (CD) were applied on the trees. Bark stripping is expected to affect water metabolism of leaves and therefore changes in the EIS parameters are expected as well. Single-DCE (ZARC) model was used as equivalent circuit for leaves. Several electrophysiological parameters of this model were compared with moisture content (MC) of the leaves. Intracellular resistance $\left(\mathrm{R}_{\mathrm{i}}\right)$, extracellular resistance $\left(\mathrm{R}_{\mathrm{e}}\right)$ and relaxation time $(\tau)$ of the leaves increased during 14 days after stripping while the distributed coefficient $(\Psi)$ and $\mathrm{MC}$ decreased. Significant correlation between EIS parameters, MC and trees treatments were found.
\end{abstract}

Keywords: Quercus suber, Electrical impedance, Equivalent circuit, Single DCE, Leaves, Barkstripping, Bark-stripping coefficient.

\section{INTRODUCTION}

It is predicted that the cork extraction is extremely traumatic for cork oak trees; it exposes a considerably part of living tissues and causes an extensive wound (Natividade 1950). The effect of bark stripping is very complex; the large amount of water lost from the stripped surface is most likely to influence the water balance and, directly or indirectly, limits the physiological processes (Correia et al. 1992). Several methods are used to assess the effect of stripping intensity on Quercus suber trees e.g. chlorophyll fluorescence emission and the stomatal conductance of leaves (Correia 1992, Werner and Correia 1996), tree diameter growth and its seasonal pattern either in very young cork oak trees (Fialho et al. 2001) or in mature trees under bark production (Costa et al. 2004). Despite numerous studies on Quercus suber trees, after stripping, there has been made no (or little) attempt to relate the effect of bark stripping on the dehydratation stress of the leaves.

EIS has been used to study stress reaction in plants (Repo et al. 1994, 2000; Väinölä and Repo 2000; Laarabi et al. 2005a, 2005b). The method provides information about the physicochemical properties of cellular structure.

For EIS studies the sample is set in an alternating electric field with small amplitude of current passing through the sample. When changes in the amplitude and phase of the alternating current are transformed into the complex plane, they induce an impedance spectrum, with frequency as an intrinsic variable. In biological samples, the proportion of current passing through the extracellular

\footnotetext{
${ }^{1}$ Equipe Sciences du bois, Faculté des Sciences de Rabat, Université Mohammed V - Agdal. 4, Avenue Ibn Battouta B.P. 1014 Rabat, Morocco. ${ }^{2}$ Laboratoire de Physiologie et des biotechnologies végétales, Faculté des Sciences de Rabat, Université Mohammed V - Agdal. 4, Avenue Ibn Battouta B.P. 1014 Rabat, Morocco. chokairi@fsr.ac.ma

${ }^{3}$ Centre de Recherche Forestière. BP 763, Agdal-Rabat, Morocco. afamiri2001@yahoo.fr

${ }^{4}$ Laboratoire de Mécanique et Génie Civil, Université Montpellier 2, CNRS UMR 5508, CC 048 Place Eugène Bataillon, 34095 Montpellier, France. joseph.gril@univ-montp2.fr Corresponding author: •ahakam@fsr.ac.ma Received: 20.10.2011 Accepted: 23.03.2012
} 
spaces (intercellular spaces between the cells) and intracellular spaces in tissues depends on the alternating current (AC) frequency. At low frequency, AC passes through the extracellular space. The cell membranes become more conductive as current frequency increases (Repo et al. 2004) and accordingly, the amount of intracellular current increases. Therefore, information about different tissues features, i.e., intra and extracellular fluids may be revealed by EIS (Väinölä and Repo 2000). Several stressors affect the EIS parameters of plants organs. The $\tau$ and the $\mathrm{R}_{\mathrm{i}}$ correlate with cold hardening in Scots pine, $\mathrm{R}_{\mathrm{e}}$ and $\tau$ decreases with increases in cellular injuries caused by frost (Repo et al. 1994), the $R_{e}$ correlates with frost-expose in rhododendron leaves (Väinölä and Repo 2000). The stripping, with all its implications in physiological processes (Pinto et al. 2006) may lead to considerable water losses (Correia et al.1992).

Because EIS is sensitive to changes in the physicochemical properties of cells we hypothesized that cellular deterioration in cork oak leaves caused by water balance disturbance after stripping will alter some EIS parameters as has been observed for other stressors (e.g., Repo et al. 1994, 2000).

\section{MATERIAL AND METHOD}

\section{Plant material}

The study was carried out on young leaves of mature Quercus suber L. trees at site A VII-5 (Canton A, Perimeter VII and Plot 5) of western Mamora forest $\left(6^{\circ} 45^{\prime} \mathrm{O}, 34^{\circ} 2^{\prime} \mathrm{N}, 30 \mathrm{~m}\right.$ of altitude), Rabat, Morocco. Mamora soil is made of a clay layer on which we have red or pink colour sand layer. The average annual precipitations is $500 \mathrm{~mm}$ and the average temperature in summer (June, July, August and September) oscillate around $23^{\circ} \mathrm{C}$. Six mature and productive cork oak trees representative of the dominant and typical tree in that field were selected and numbered $T_{1}$ to $T_{6} .2$ non stripped trees were served as controls $\left(\mathrm{T}_{1}\right.$ and $\left.\mathrm{T}_{2}\right)$; two trees $\left(\mathrm{T}_{3}\right.$ and $\left.\mathrm{T}_{4}\right)$ stripped for the first time with $\mathrm{CD}$ respectively 1.1 and 1.22, the two other trees $\left(\mathrm{T}_{5}\right.$ and $\left.\mathrm{T}_{6}\right)$ bark-stripped one time with $\mathrm{CD}$ respectively 1.64 and 1.74. All these trees were regenerated by reject of stump after ablation of the trunk. Bark stripping characteristics of these trees are outlined in table 1.

Table 1. Stripping Characteristics of the trees under study. ND: number of bark-stripping, it is the number of time that the tree was stripped, CD: Bark stripping coefficient calculated as the ratio of the maximum length by over the trunk perimeter at breast height (Natividade 1950).

\begin{tabular}{|c|c|c|c|l|}
\hline Tree & Age (Year) & ND & CD & \multicolumn{1}{|c|}{ Remarks } \\
\hline T1 & 35 & 0 & 0 & Non-stripped \\
\hline T2 & 45 & 0 & 0 & Non-stripped same stump as T5 \\
\hline T3 & 45 & 1 & 1.11 & same stump as T4 and T6 \\
\hline T4 & 45 & 1 & 1.22 & same stump as T3 and T6 \\
\hline T5 & 45 & 2 & 1.64 & same stump as T2 \\
\hline T6 & 45 & 2 & 1.74 & same stump as T3 and T4 \\
\hline
\end{tabular}

\section{Impedance measurements}

EIS of leaves was performed in summer 2009 (before and after bark-stripping period). There were five sampling dates, i.e., on July 7, (few hours before stripping), July 14, (seven days after stripping), July 22, (fourteen days after stripping), 7 august (thirty days after stripping), August 27, (fifty days after stripping). From each tree and at each sampling date, one short shoot was sampled each time from branches located in the central crows of the tree. The leaves were placed in the plastic bags immediately after sampling and transported to the laboratory. The leaves were oriented vertically 
when running the impedance measurements. Impedance spectra were measured with an $\mathrm{Ag} / \mathrm{AgCl}$ cell connected to a Hewlett-Packard $3330 \mathrm{LCZ}$ meter. The Ag/AgCl electrodes were kept in contact with the samples using a conductive paste (3M red Dot Foam Monitoring Electrode 2237-3, of the type commonly used for electrocardiograms) to maintain minimum electrode tissue interface polarization. Further, the device was calibrated by using OPEN/SHORT circuit correction to eliminate the effect of electrodes- paste interface. The real $\left(Z_{r}\right)$ and imaginary $\left(Z_{i}\right)$ values of impedance were then measured within a frequency range of $40 \mathrm{~Hz}$ to $100 \mathrm{kHz}$. The input voltage of the signal was $30 \mathrm{mV}$ (rms). The section of the conductive part of electrodes was $0.78 \mathrm{~cm}^{2}$ corresponding to a disk of $1 \mathrm{~cm}$ of as diameter. From each short shoot, 3 young leaves were selected and numbered $\mathrm{L}_{1}$ to $\mathrm{L}_{3}$. $\mathrm{L}_{1}, \mathrm{~L}_{2}$ and $\mathrm{L}_{3}$ were respectively the first, the second and the third leaf formed on the short shoot. The three leaves were tested and a leaf thickness was measured with a digital Mitutoyo Calipers $0.01 \mathrm{~mm}$. All the tested leaves had an area of more than $0.78 \mathrm{~cm}^{2}$ and with naked eye; they presented no sign of aging.

\section{Determination of MC of leaves}

After the impedance measurements, the specimen were weighed and dried at $100^{\circ} \mathrm{C} \pm 3$ for $24 \mathrm{~h}$. The scale of $1 \mathrm{mg}$ accuracy was used in weighing. The MC of leaves was calculated as:

$$
M C=\frac{100 \times\left(M_{H}-M_{0}\right)}{M_{0}}
$$

Where $M_{H}$ is weight of leaves and $M_{0}$ is the oven dry weight after drying at $100^{\circ} \mathrm{C}$ for $24 h$.

\section{Modelling of leaves impedance}

Impedance analysis in plants is performed using mainly two types of equivalent circuits i.e., lumped (Harker and Maindonald 1994) and distributed models (Repo et al. 1994, 2000, Stout 1988, Mancuso 1999, Mizukami 2007). In this study, the mathematical model ZARC illustrated by the circuit diagram in figure 1 was fitted to the data. The ZARC comprises includes a distributed circuit element (DCE) in series with a resistor $\left(\mathrm{R}_{\infty}\right)$. The DCE element comprises includes a Constant Phase Element $(\mathrm{CPE})$ in parallel with a resistor $(\mathrm{R})$.

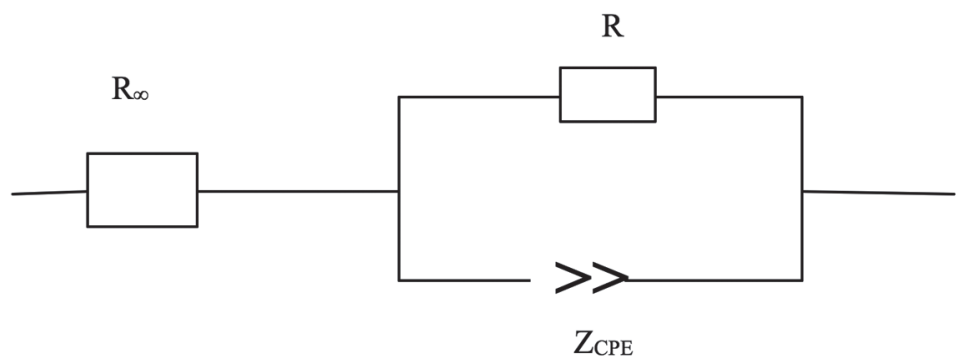

Figure 1. Single-DCE (ZARC) model for leaves.

The CPE impedance is defined as:

$$
Z_{C P E} ; \frac{1}{(i \propto C)^{x}}
$$


The impedance of single DCE is defined as follows:

$$
Z_{Z A R C}=\frac{R}{1+(i \tau \omega)^{\psi}}+\mathrm{R}_{\infty}
$$

The real and imaginary parts of impedance obtained from equation (3) are expressed respectively as (see appendix 2 for more explanations):

$$
\begin{aligned}
& \operatorname{Re} \operatorname{al}(Z)=R_{\infty}+\frac{R\left[1+(\omega \tau)^{\psi} \cos \psi \frac{\pi}{2}\right]}{2\left(1+(\omega \tau)^{\psi} \cos \psi \frac{\pi}{2}\right)} \\
& \operatorname{Im} g(Z)=-\frac{R\left[(\omega \tau)^{\psi} \sin \psi \frac{\pi}{2}\right]}{2\left(1+(\omega \tau)^{\psi} \cos \psi \frac{\pi}{2}\right)}
\end{aligned}
$$

Parameter $\Psi$ is defining if the center of the arc is below $\mathrm{x}$-axis or not.

The angle between $\mathrm{x}$ axis and the line passing by the center and the origin of the axes was as and $\alpha$ and $\Psi$ is defined as:

$$
\psi=1-\frac{2 \alpha}{\pi}
$$

The total complex impedance $(\mathrm{Z})$ of the model of figure 1 is as shown (for derivation of this equation see Appendix 1):

$$
Z=R_{\infty}+Z_{Z A R C}
$$

By increasing the $\Psi$ value, the impedance spectrum approaches a symmetric arc (attained when $\Psi=1)$.

$\mathrm{R}_{\mathrm{e}}$ was calculated as:

$$
R_{e} ; R_{\Gamma} * R
$$

$R_{\infty}$ represents the resistance at high frequency 
The $R_{i}$ was calculated as:

$$
R_{i}=R_{\infty}\left(1+\left(R_{\infty} / R\right)\right)
$$

And the relaxation time as:

$$
\tau=1 / 2 \pi f_{c}
$$

The specific resistances: intracellular specific resistance $\mathrm{r}_{\mathrm{i}}$ (unit $\Omega \mathrm{m}$ ) and extracellular specific resistance $r_{e}$ (unit $\Omega m$ ) were obtained by normalization of the measured resistance $\left(R_{i}\right.$ and $R_{e}$ in respect of the cross-sectional area $\left(A_{s}\right)$ and the thickness of the leaf $\left.(e)\right)$.

$$
r_{i}=\frac{A_{S}}{e} R_{i}
$$

and

$$
r_{e}=\frac{A_{S}}{e} R_{e}
$$

In the text, capital letters refer to non normalized parameters and lower case letters to normalized values. $\tau$ and its $\Psi$ did not need normalization.

$\mathrm{A}_{\mathrm{s}}=0.76 \mathrm{~cm}^{2}$ and e approximately $0.3 \mathrm{~mm}$, which gives $\mathrm{r}_{\mathrm{i}} \approx 0.26 \mathrm{R}_{\mathrm{i}}$ and $\mathrm{r}_{\mathrm{e}} \approx 0.26 \mathrm{R}_{\mathrm{e}}$.

The non normalized and normalized parameters are of similar magnitude. We will continue to use $R_{i}$ and $R_{e}$ for the rest of the work.

Equivalent circuit parameters of the distributed circuit model (single-DCE, figure 1) were estimated by using the method of non-linear least squares curve-fitting program using Microsoft Excel.

\section{Statistical analysis}

Relations between the leaves properties and electrical parameters were studied. The Pearson correlation coefficient $(r)$ was calculated and the t-test was used to estimate the significance of correlation. Statistical analyses were carried out with SPSS software.

\section{RESULTS}

The graph representing $Z_{i}=f\left(Z_{r}\right)$ in complex plane between $40 \mathrm{~Hz}$ to $100 \mathrm{kHz}$ for three young leaves from the same branch of the tree number 4 are presented (Figure 2). The impedance spectrum of every leaf had a single arc in the form of parabola where the top corresponds to the frequency value characteristic of material $f_{c}$ and the intersection of the parabola with the $x$ axis gives $\mathrm{R}_{\infty}$ and the Re. The radius of the arc increased with increase in leaf maturity. 


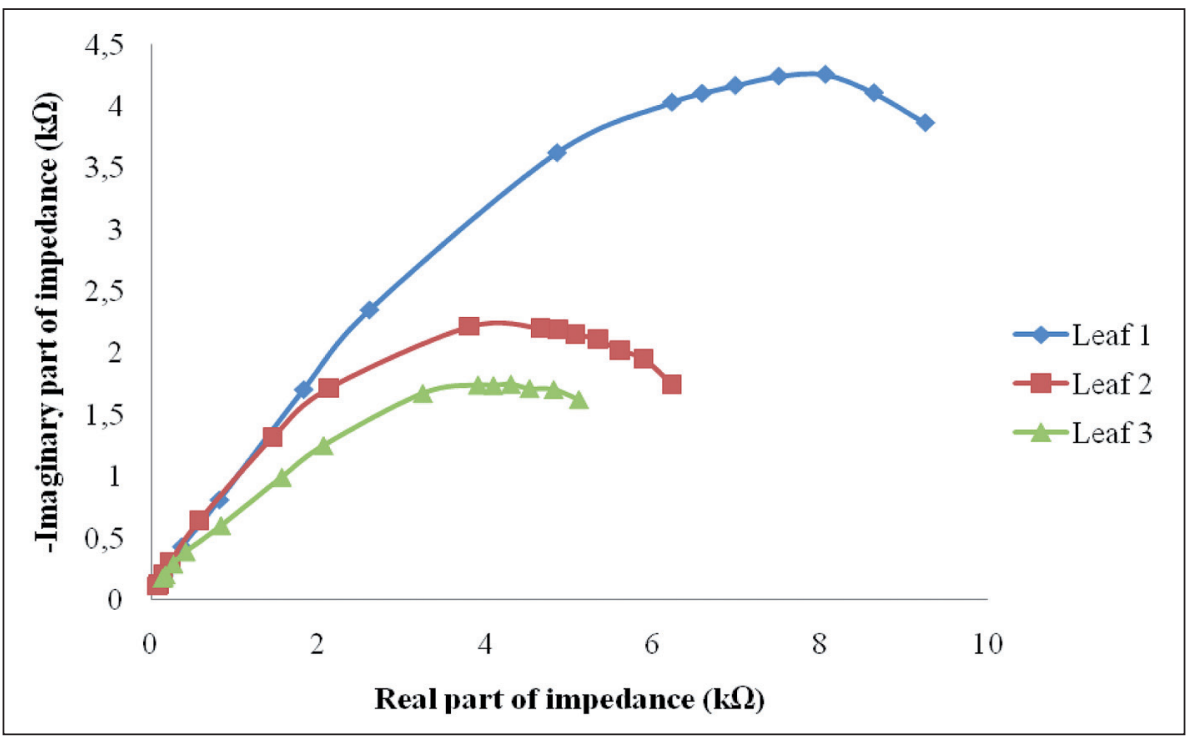

Figure 2. Typical impedance spectra of cork oak young leaves at different stages of maturity.; $\mathrm{L}_{1} \mathrm{~L}_{2}$ and $\mathrm{L}_{3}$ were respectively the first, the second and the third leaf formed on the short shoot of the tree number 4 . The spectra are composed of 35 different frequencies ranging from $40 \mathrm{~Hz}$ to $100 \mathrm{kHz}$ (from right to left, respectively).

The single ZARC model fitted the spectra well (figure 3).

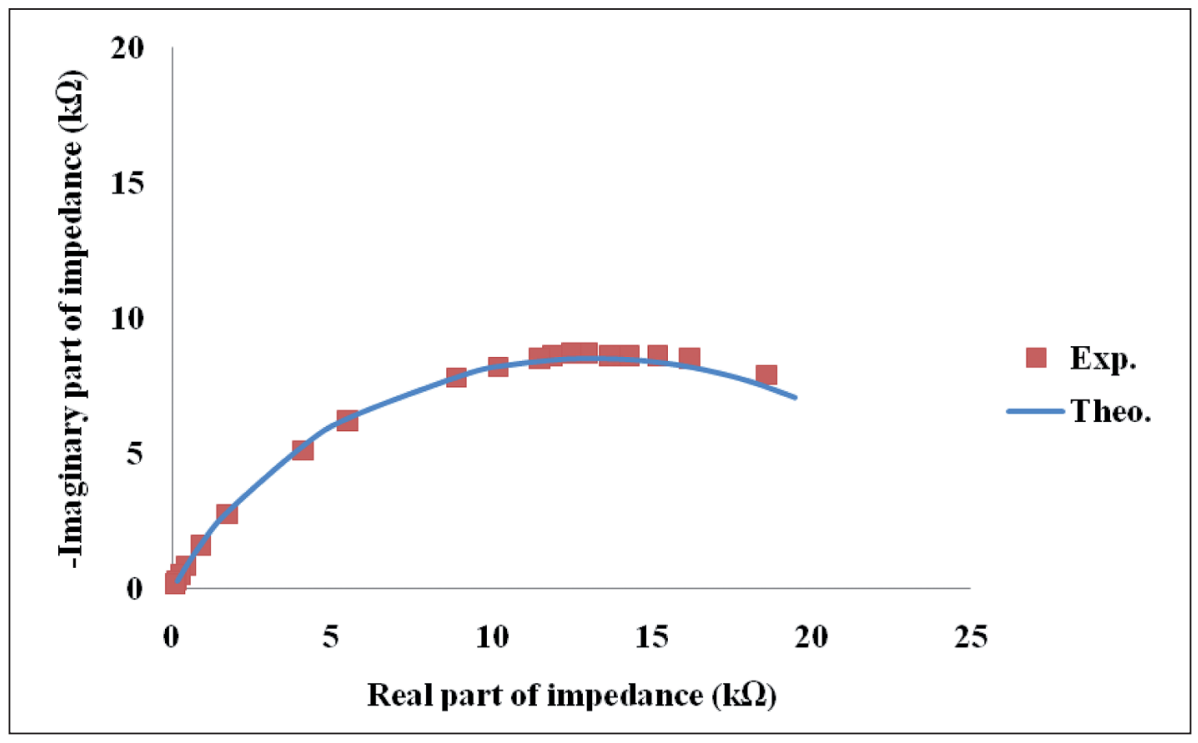

Figure 3. Experimental and theoretical values obtained from equivalent circuit of the first leaf $\left(\mathrm{L}_{1}\right)$ formed on the short shoot of the tree number 3. Frequency increases from right $(40 \mathrm{~Hz})$ to left $(100 \mathrm{KHz})$. 
All resistance and $\tau$ parameters increased during the study (figure 4). The $R_{i}$ was $60 \Omega$ at the beginning of July (before bark stripping) and rose up to $105 \Omega$ in August (figure $4 \mathrm{a}$ ). The extracellular resistances typically were the lowest $(35 \mathrm{k} \Omega$ ) at the bark stripping date and then increased (figure $4 \mathrm{~b}$ ), $\tau$ inreased slightly from $1.33 \mathrm{~ms}$ to $1.81 \mathrm{~ms}$ after bark-stripping (figure $4 \mathrm{c}$ ); i.e. the characteristic frequency $f c$ decreased from 120 to $88 \mathrm{~Hz}$. Comparatively to intracellular resistance we noticed a slight increase $\mathrm{R}_{\mathrm{e}}$ already seven days after bark-stripping, however, 14 days after stripping, there was a strongly difference between the variations of intra and extracellular resistance (98\% and 75\% respectively) (figure $4 \mathrm{a}$ and $4 \mathrm{~b}$ ). The exponent $\Psi$ increased during experiments (from 0.63 to 0.78 ) (figure $4 \mathrm{~d}$ ). Leaves $\mathrm{MC}$ was the highest for all treatements at beginning of the study and then tapered off (figure 4e).

$\mathrm{CD}$ had a significant effect on all EIS parameters and $\mathrm{MC}(\mathrm{P}<0.01)$. There was good correlation between MC and all EIS parameters except for $\Psi$ (Table 2). Our results also demonstrated the importance of sampling date on EIS parameters (Table 2) and (figure 5), espacially on the intracellular resistance figure 5 a.
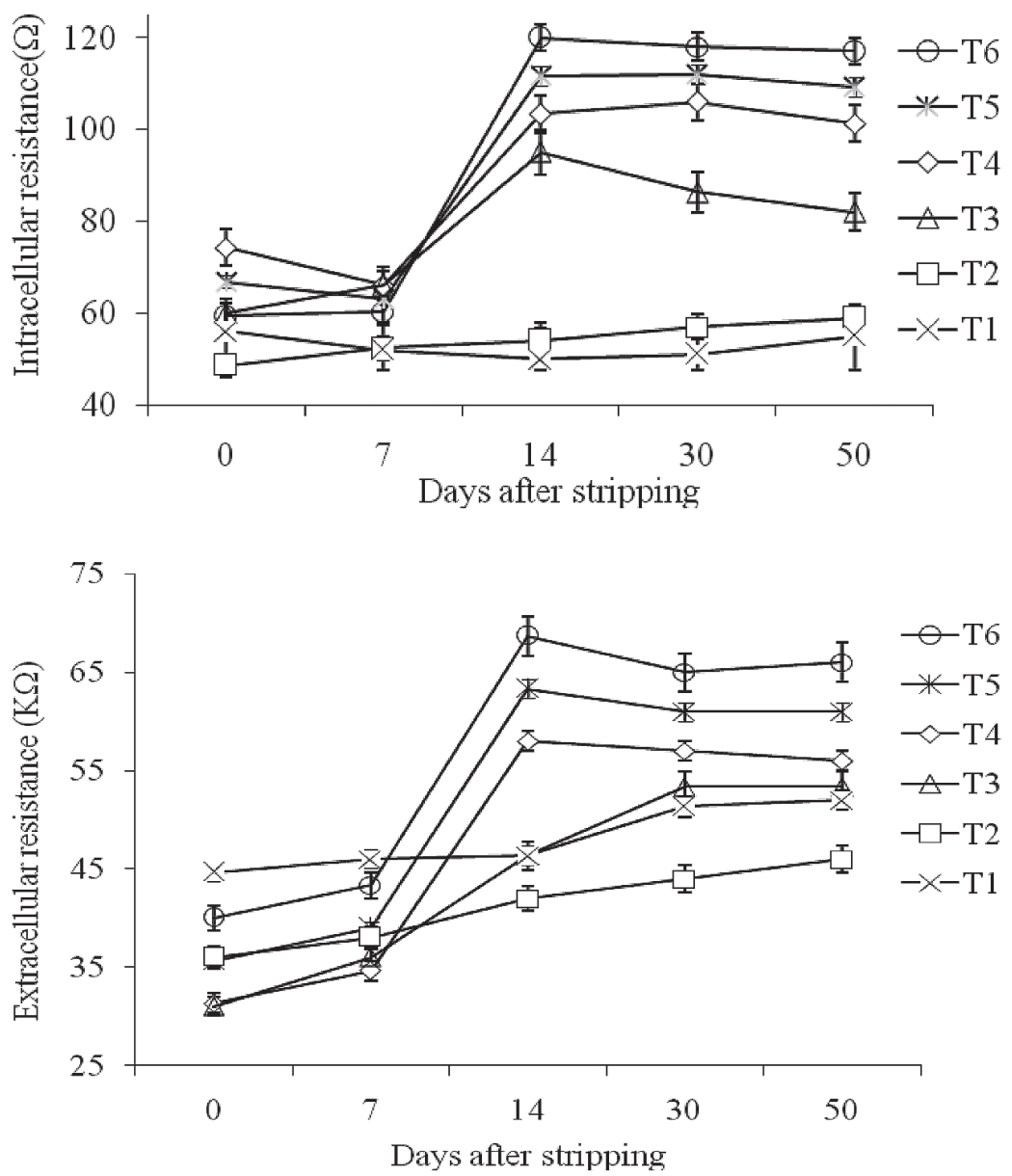

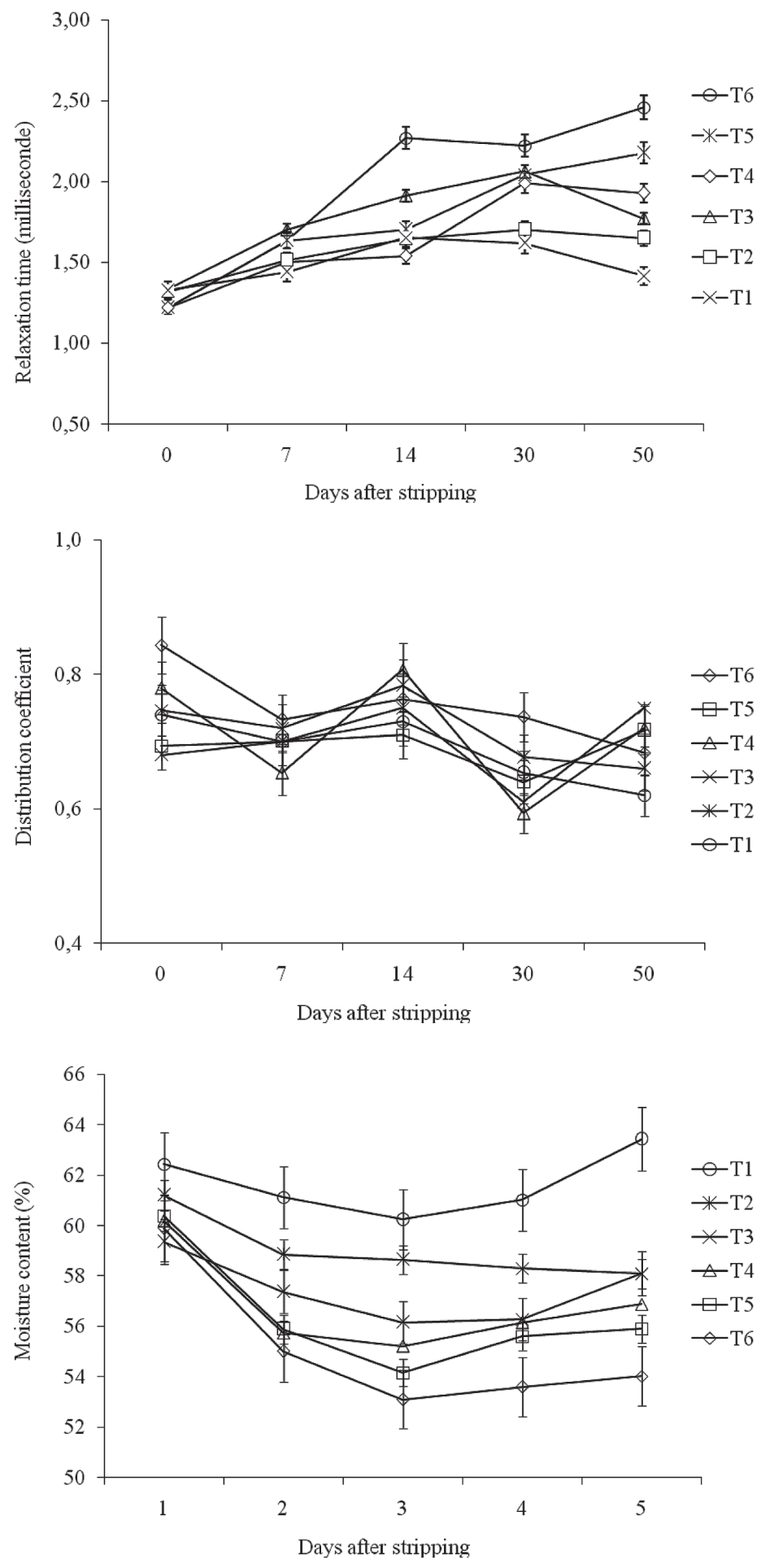

Figure 4. Changes in the parameters for a single-DCE model for the Quercus Suber young leaf by impedance analysis and dry mater content in the leaf.

$\mathrm{T}_{1}$ and $\mathrm{T}_{2}$ served as reference trees, $\mathrm{T}_{3}$ and $\mathrm{T}_{4}$, bark-stripped for the first time with $\mathrm{CD}$ respectively 1.1 and $1.22, \mathrm{~T}_{5}$ and $\mathrm{T}_{6}$ bark-stripped one time with $\mathrm{CD}$ respectively 1.64 and 1.74 . Bars indicated standard errors. 


\section{DISCUSSION}

It is shown that the theoretical values are in good agreement with the experimental ones. The occurrence of one arc in a typical impedance spectrum for the leaves and the satisfactory fit of the single DCE model strongly indicate the suitability of the model in the study of leaves. This result is in agreement with the previous studies of olives leaves (Mancuso 1999), Rhododendron leaves (Väinölä and Repo 2000) or of silver birch leaves (Repo et al. 2004).

Cellular responses of cork oak young leaves to stress caused by bark stripping were detected by EIS, and the different EIS parameters were sensitive to different factors. The effects of bark stripping were more evident 21 days after bark stripping.

The increase of intra and extracellular resistances could be in relation with water losses after stripping, actually as demonstrated by Repo et al. (2007) the drying of the cells may be enhanced by a reduction in the transpiration stream after leaf abscission, subsequently leading to an increase in both resistances parameters.

The increase of intracellular resistance during the summer additionally with the stripping effect could indicate a decrease in electrolytic content and the increase in cell sugar. In fact, as mentioned by Mancuso (1999), the decrease of intracellular resistance in olives leaves during winter was a result of an increase in electrolytic content and a decrease in cell sugar concentration.

The difference between intra- and extracellular increases ( $98 \%$ and $75 \%$ respectively) 14 days after sttripping can partly be explained by forces binding water molecules in the cell. In fact, extracellular water (water in intercellular spaces between the cells) is strongly bound by imbibition force whereas intracellular water is retained by osmotic type force. The decrease in all resistances 21 day after bark stripping can be explained by plant reaction to balance water deficit by stomatal regulation (openning and closing the stomates); water losses are reduced and the plant tends to find its moisture.

The increase of relaxation time $\left(\tau=1 / 2 \pi f_{c}\right)$ with higher stripping coefficient meant that the characteristique frequency value $\left(f_{c}\right)$ moved toward lower frequencies.

Changes in relaxation time suggest a change in cell membrane (cf. Repo et al. 2004). Accordingly, we concluded that excessive stripping may affect the frequency response of cell membranes. The distribution coefficient has the mean for about 0.71 in cork oak leaves versus 0.66 in silver birch leaves (Repo et al. 2004) and 0.61 in tea leaves (Mizukami 2007). In the dielectric materials which consists of different types of molecules, e.g. biological samples, multiples sources may contribute to this parameter, including biological variability, cell orientation anisotropy, intracellular heterogeneity, multiple component structures and the existence of a range of different relaxation processes (Repo et al. 2004). In isotropic samples with even sizes, e.g. water molecules, the impedance arc is almost a semicircle and the distributed coefficient is close to 1 (Torgovnikov 1993). The value of $\psi$ in cork oak leaves suggest that several interfaces exist that fact also affect the relaxation time.

Moisture content and all electrical parameter curves aim to an asymptote 21 days after bark stripping. They are two explanations for this phenomenon: either the reaction of the tree to balance its hydric gap by progressive decrease of transpiration at the level of the leaves (Correia et al.1992), or as referred to Natividade (1950), by the formation of a new phellogen layer with immediate cork regeneration function which, due to cork's impermeability, limits the water losses by evaporation.

The time of sampling was important for EIS parameters of cork oak leaves especially on the $7^{\text {th }}$ of August i.e. 30 days after bark stripping (table 2). $\mathrm{R}_{\mathrm{i}}$ is the electrical parameter which had higher Pearson coefficient with MC, CD and ND. 

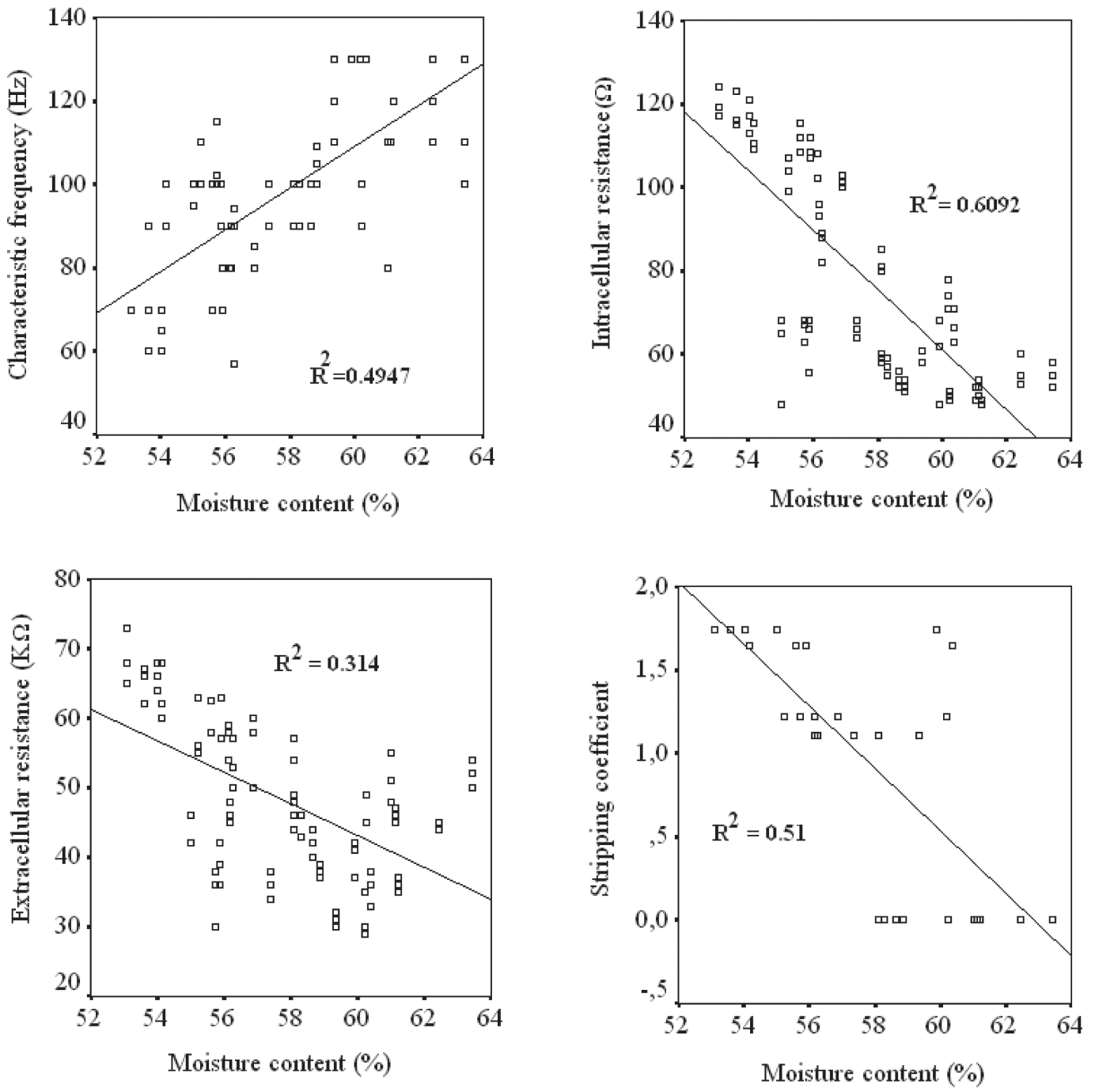

Figure 5. EIS parameters as function moisture content.

Table 2. The Pearson correlation coefficient ( $r$ ) of the linear regression model for the comparison of the EIS and the (MC) with different treatments at dates when the correlation was signifiant. The EIS parameters were obtained by simple-DCE model. (). The correlation coefficient was calculated using the pooled data of all trees and test dates $(n=75)$ and at different date separately $(n=18)$ (Asterisks indicate statistically significant differences $\left({ }^{\star} \mathrm{P}<0.05,{ }^{\star \star} \mathrm{P}<0.01\right)$

\begin{tabular}{|c|c|c|c|c|c|c|}
\hline & \multirow{2}{*}{$\begin{array}{l}\text { Pooled } \\
\text { data }\end{array}$} & \multicolumn{5}{|c|}{ Pearson correlation coefficient(r) at different dates } \\
\hline & & July 8 & July 14 & July 22 & August 7 & $\begin{array}{l}\text { August } \\
27\end{array}$ \\
\hline \multicolumn{7}{|c|}{ (A)EIS parameters versus CD } \\
\hline $\mathrm{R}_{\mathrm{i}}-\mathrm{CD}$ & $0.728 * *$ & & $0.61 * *$ & $0.88 * *$ & $0.81 * *$ & $0.73 * *$ \\
\hline $\mathrm{R}_{\mathrm{e}}-\mathrm{CD}$ & $0.350 * *$ & & & $0.77^{* *}$ & $0.85^{* *}$ & $0.81^{* *}$ \\
\hline$\tau-\mathrm{CD}$ & $0.394 * *$ & $0.62 * *$ & $0.50^{*}$ & & $0.51^{*}$ & $0.88 * *$ \\
\hline $\mathrm{f}_{\mathrm{c}}-\mathrm{CD}$ & $-0.35 * *$ & $0.65 * *$ & $-0.49 *$ & & $-0.57^{*}$ & $-0.88^{*}$ \\
\hline
\end{tabular}




\begin{tabular}{|l|l|l|l|l|l|l|}
\hline \multicolumn{6}{|l|}{$(\mathrm{B})$ EIS parameters versus CD } \\
\hline $\mathrm{R}_{\mathrm{i}-\mathrm{ND}}$ & $0.688^{* *}$ & & $0.54^{*}$ & $0.79^{* *}$ & $0.73^{* *}$ & $0.65^{* *}$ \\
\hline $\mathrm{R}_{\mathrm{e}}-\mathrm{ND}$ & $0.374^{* *}$ & & & $0.86^{* *}$ & $0.83^{* *}$ & $0.82^{* *}$ \\
\hline$\tau-\mathrm{ND}$ & $0.438^{* *}$ & $-0.56^{*}$ & $0.58^{*}$ & $0.54^{*}$ & $0.56^{*}$ & $0.89^{* *}$ \\
\hline $\mathrm{f}_{\mathrm{c}}-\mathrm{ND}$ & $-0.35^{*}$ & $0.59^{* *}$ & $-0.56^{*}$ & $-0.52^{*}$ & $-0.58^{*}$ & $-0.87^{*}$ \\
\hline$(\mathrm{C})$ EIS parameters versus MC & \multicolumn{7}{l}{} \\
\hline $\mathrm{R}_{\mathrm{i}}-\mathrm{MC}$ & $-0.788^{* *}$ & & $-0.63^{* *}$ & $-0.83^{* *}$ & $-0.84^{* *}$ & $-0.73^{* *}$ \\
\hline $\mathrm{R}_{\mathrm{e}}-\mathrm{MC}$ & $-0.519^{* *}$ & $0.67^{* *}$ & & $-0.84^{* *}$ & $-0.66^{* *}$ & $-0.60^{* *}$ \\
\hline$\Psi$-MC & & & & & & $-0.55^{*}$ \\
\hline $\mathrm{f}_{\mathrm{c}}-\mathrm{MC}$ & 0.71 & & $0.49^{*}$ & $0.49^{*}$ & 0.68 & $0.90^{* *}$ \\
\hline$(\mathrm{C}) \mathrm{MC}$ versus CD and ND & $-0.741^{* *}$ & $-0.71^{* *}$ & $-0.93^{* *}$ & $-0.97^{* *}$ & $-0.88^{* *}$ & $-0.83^{* *}$ \\
\hline $\mathrm{MC}-\mathrm{CD}$ & $-0.735^{* *}$ & $-0.69^{* *}$ & $-0.88^{* *}$ & $-0.96^{* *}$ & $-0.86^{* *}$ & $-0.82^{* *}$ \\
\hline $\mathrm{MC}-\mathrm{ND}$
\end{tabular}

\section{CONCLUSION}

In conclusion, this was the first time that EIS was applied to study the effect of bark stripping on the dehydration stress of the Quercus suber L. leaves. Impedance parameters were significantly sensible to physiological variations in the leaves that were associated with stresses caused by bark stripping. Intra and extracellular resistance increase as moisture content decreases and increase as bark stripping coefficient increase. According to this technique, the trees seemed to balance their hydric gap 21 days after stripping. However, bark stripping occurred during the summer when trees were already subjected to other environmental stresses; consequently, there were a great number of variables over which we had no control. Further research is needed to evaluate the so called speed of balance hydric gap with an aim to define specific bark stripping coefficient for each tree depending on the tree characteristics.

\section{ACKNOWLEDGEMENT}

The authors would like to express sincere gratitude to TWOWS (Third World Organization for Women in Science) and AIDS (Swedish International Development Cooperation Agency) for their materiel and intellectual contributions and thank Mr. Abdelhak El Abid for his idea and the fruitful discussions.

\section{REFERENCES}

Correia, O. A.; Oliveira, G.; Martins-Loucão, M. A; Catarino, F. M. 1992. Effects of barkstripping on the water relations of Quercus suber L. Scientia Gerundensis 18:195-204.

Costa, A.; Pereira, H,; Oliveira, A. 2004. The effect of cork-stripping damage on diameter growth of Quercus suber L. Forestry 77(1):1-8.

Fialho, C.; Lopes, F.; Pereira, H. 2001. The effect of cork removal on the radial growth and phenology of young cork oak trees. Forest Ecology and Management 141:251-258.

Harker, F. R.; Maindonald, J. H. 1994. Ripening of nectarine fruit, changes in the cell wall, Vacuole, and membranes detected using electrical impedance measurements. Plant Physiol. 106:165171. 
Laarabi, S.; EL Kinani, K.; Ettouhami, A.; Limouri, M. 2005a. Impédance in vivo des organes aériens de certaines plantes mono- et dicotylédones. C. R. Biologies 328:253-262.

Laarabi, S.; EL Kinani, K.; Ettouhami, A.; Limouri, M. 2005b. Analyse spectrométrique, in vivo, de l'impédance électrique de la première feuille de maïs (Zea mays L.) en fonction des conditions hydriques du sol et de latmosphère. C. R. Biologies 328:493-503.

Macdonald, J. R. 1987. Impedance spectroscopy: emphasizing solid materials and systems. New York: John Wiley \& Sons, Inc 368 p.

Macdonald, J. R. 1990. Impedance spectroscopy: old problems and new developments. Electrochim. Acta 35(10):1483-1492.

Macdonald, J. R. 1995. Exact and Approximate Nonlinear Least Squares Inversion of Dielectric Relaxation Spectra. J. Chem. Phys. 102:6241-6250.

Mancuso, S. 1999. Seasonal dynamics of electrical impedance parameters in shoots and leaves relate to rooting ability of olive (Olea europaea) cuttings. Tree physiology 19:95-101.

Mizukami, Y.; Yamada, K.; Sawai, Y.; Yamaguchi, Y. 2007. Measurement of fresh tea leaf growth using electrical impedance spectroscopy. Agricultural journal 2(1):134-139.

Natividade, J. V. 1950. Subericultura. Ministerio de Economia, Direcção General dos Serviços Florestais e Aquicolas. Lisboa, 387 p.

Pinto, Teresa M.; Torres-Pereira, José M. G. 2006. Bark stripping in cork oak (Quercus suber L.): effect of an antitranspirant application on gas exchange and water relations of the stripped surface. Trees 20:247-252.

Repo, T.; Zhang, M. I. N.; Ryyppö, A.; Vapaavuori, E.; Sutinen, S. 1994. Effects of freeze-thaw injury on parameters of distributed electrical circuits of stems and needles of Scots pine seedlings at different stages of acclimation. J. of Exp. Bot. 45:823-833.

Repo, T.; Zhang, G.; Ryyppö, A.; Rikala, R. 2000. The electrical impedance spectroscopy of Scots pine (Pinus sylvestris L) shoots in relation to cold acclimation. J. of Exp. Bot. 51(353):2095-2107.

Repo, T.; Oksanen, E.; Vapaavuori, E. 2004. Effects of elevated concentrations of ozone and carbon dioxide on the electrical impedance of leaves of silver birch (Betula pendula) clones. Tree physiology 24:833-843.

Repo, T.; Sutinen, S.; Nöjd, P.; Mäkinen, H. 2007. Implications of delayed soil frost thawing on the physiology and growth of Norway spruce. Scandinavian Journal of Forest Research 22:118-127.

Torgovnikov, G. I. 1993. Dielectric properties of wood and wood-based materials. Springer-Verlag, New York $196 \mathrm{p}$.

Stout, D. G. 1988. Effect of cold acclimation on bulk tissue electrical impedance: I Measurements with birdsfoot trefoil at subfreezing temperatures, Plant Physiol. 86(1): 275-282.

Väinölä, A.; Repo, T. 2000. Impedance spectroscopy in frost hardiness evaluation of Rhododendron leaves. Annals of Botany 86:799-805.

Werner, C.; Correia, O. 1996. Photoinhibition in cork-oak leaves under stress: Influence of the bark-stripping on the chlorophyll fluorescence emission in Quercus suber L. Trees 10:288-292 


\section{APPENDIX 1}

The single DCE is composed of one distributed element (DCE) in series witk a resistor $(\mathrm{R} \infty)$. The DCE is composed of a parallel arrangement of a resistor $\mathrm{R}$ and a constant phase element (CPE) (figure 1). The impedance of the constant phase element is (Macdonald 1987, 1990, 1995):

$$
Z_{C P E}=\frac{1}{(i \omega C)^{\psi}}
$$

For the impedance of the DCE we get:

$\frac{1}{Z_{D C E}}=\frac{1}{R}+\frac{1}{Z_{C P E}}$

Then $Z_{D C E}=\frac{R}{1+R(i \omega C)^{\psi}}=\frac{R}{1+\left(i \omega C R^{1 / \psi}\right)^{\psi}}$

When we define $\tau=C R^{1 / \psi}$, we get $Z_{D C E}=\frac{R}{1+(i \omega \tau)^{\psi}}$

For the total impedance of Single-DCE model we get :

$$
Z=R_{\infty}+Z_{D C E}=R_{\infty}+\frac{R}{1+(i \omega \tau)^{\psi}}
$$

\section{APPENDIX 2}

Working expression for equivalent circuit modeling according to the expressions 7 and 8

$$
\begin{aligned}
& Z_{\text {zarc }}=R_{\infty}+\frac{R}{1+(i \omega \tau)^{\psi}}=\operatorname{Re} a l(Z)+i \operatorname{Im} g(Z) \\
& =R_{\infty}+\frac{R}{1+(\omega \tau)^{\psi}\left(\cos \psi \frac{\pi}{2}+i \sin \psi \frac{\pi}{2}\right)} \\
& =R_{\infty}+\frac{R\left[1+(\omega \pi)^{\psi} \cos \psi \frac{\pi}{2}-i(\omega \pi) \sin \psi \frac{\pi}{2}\right]}{\left(1+(\omega \tau)^{\psi /} \cos \psi \frac{\pi}{2}\right)^{2}+\left((\omega \tau)^{\psi} \sin \psi \frac{\pi}{2}\right)^{2}} \\
& =R_{\infty}+\frac{R\left[1+(\omega \tau)^{\psi} \cos \psi \frac{\pi}{2}-i(\omega \tau)^{\psi} \sin \psi \frac{\pi}{2}\right]}{1+2(\omega \tau)^{\psi /} \cos \psi \frac{\pi}{2}+\left((\omega \tau)^{\psi /} \cos \psi \frac{\pi}{2}\right)^{2}+\left((\omega \tau)^{\psi} \sin \psi \frac{\pi}{2}\right)^{2}}
\end{aligned}
$$




$$
\begin{aligned}
& =R_{\infty}+\frac{R\left[1+(\omega \pi)^{\psi} \cos \psi \frac{\pi}{2}-i(\omega \tau)^{\psi} \sin \psi \frac{\pi}{2}\right]}{2\left(1+(\omega \tau)^{\psi} \cos \psi \frac{\pi}{2}\right)} \\
& \operatorname{Re} \operatorname{al}(Z)=R_{\infty}+\frac{R\left[1+(\omega \tau)^{\psi} \cos \psi \frac{\pi}{2}\right]}{2\left(1+(\omega \tau)^{\psi} \cos \psi \frac{\pi}{2}\right)} \\
& \operatorname{Im} g(Z)=-\frac{R\left[(\omega \tau)^{\psi} \sin \psi \frac{\pi}{2}\right]}{2\left(1+(\omega \tau)^{\psi} \cos \psi \frac{\pi}{2}\right)} \\
& -\operatorname{Im} g(Z)=\frac{R\left[(\omega \tau)^{\psi} \sin \psi \frac{\pi}{2}\right]}{2\left(1+(\omega \tau)^{\psi} \cos \psi \frac{\pi}{2}\right)}
\end{aligned}
$$

\section{LISTE OF ABBREVIATIONS}

$C D$ : bark-stripping coefficient, is calculated as the ratio of the maximum length by the trunk perimeter at breast height

$N D$ : number of bark-stripping, is the number of time that the tree was stripped

$M C \quad$ : moisture content, \%

$R_{i} \quad$ : intracellular resistance, $\Omega \mathrm{m}$

$R_{e} \quad$ : extracellular resistance, $\Omega \mathrm{m}$

$r_{i} \quad$ : intracellular specific resistance, $\Omega \mathrm{m}$ (obtained by normalization of Ri )

$r_{e} \quad:$ extracellular specific resistance, $\Omega \mathrm{m}$ (obtained by normalization of $\mathrm{Re}$ )

$e \quad:$ thickness of the leaf, $m$

As : cross-sectional area, $\mathrm{m} 2$

$\alpha \quad$ : angle between $\mathrm{x}$ axis and the line passing by the origin of the axes and the center of the arc in the form of parabola, deg

fc : characteristic frequency value, $\mathrm{Hz}$

$\omega \quad:$ the angular frequency, radians per second

$\tau \quad:$ relaxation time, $s$

$\psi \quad:$ the distributed coefficient of relaxation time

$i \quad:$ the imaginary unit

EIS : electrical impedance spectroscopy

$D C E$ : distributed circuit element

$C P E$ : Constant Phase Element

$R \infty \quad$ : represents the resistance at height frequency 